participated in actions ranging from eviction protests and meat boycotts to combatting the regressive sales tax and demanding new schools. Orleck stressed both the considerable success of the councils' activities and their radicalizing impact on housewives.

Taken together, these papers suggest three sets of issues for further investigation. First, we need to know more about how the internal economic structures and relations of working-class neighborhoods supported local neighborhood hierarchies of power and provided resources for collective organizing inside and outside the paid workplace. Second, we need to think further about the implications of asserting workers', housewives', or youth's "autonomy" within working-class ethnic communities and to explore the negotiations, tensions, and divisions as well as solidarities that emerged when particular groups defined a new political or cultural agenda. Finally, although these papers were extremely rich in recovering new forms of working-class agency, we need to think about the consequences of these new collective strategies, which reached from the arena of international politics to the sites of domestic work and leisure. The implications of such strategies could shed new light on our analysis of working-class political and cultural priorities in the decades that followed the 1930s.

\title{
Labor and Industrialization Meeting of the Social Science History Association
}

\author{
John Cumbler \\ University of Louisville
}

The labor and industrialization meeting of the 1987 Social Science History Association comprised seven sessions. Topics ranged from the work of Charles Tilly on collective action to quantification and the future of labor history. The panels represented a variety of subjects addressing issues of class, gender, and culture. Several papers concerned women workers, and all the panels included members of both genders. This year, an attempt was made to include more non-Western panels, and the most notable among these was "Politics and Culture at the Fringes of the Industrial World." Although these presentations were excellent, unfortunately very few people attended them. At most of the other panels, however, there were enough people in attendance to carry on discussions after the presentations.

Discussion took place at the network meetings about what is or should be done in labor history and about where the network should go. Since the 1988 meeting will be in Chicago, it was suggested that a local labor history tour be included as part of the program. The organization suggested a general panel on the state of labor and industrial studies. Other proposed panels would concern the relationship between labor history and economic history, and a reevaluation of Edward Thompson's 
contribution to labor history. It was also suggested that efforts be continued to attract historians of non-Western areas.

In addition, much discussion centered on the relationship between labor history and the contemporary labor movement. A panel was suggested on the political responsibility of labor historians to the labor movement. Some of the discussants were critical of the idea, but the energy of the discussion suggested an interest in the topic.

The labor section of the convention drew a variety of papers that more than filled the allotted spots. Walter Licht (University of Pennsylvania) is the program committee representative for the labor and industrialization network for the 1988 convention. Inquiries concerning the panels should be referred to Professor Licht in care of the Department of History. Since whole panels are the easiest to manage, it is advised that prospective participants send proposals only after the panel has been assembled.

\title{
Women in Dark Times
}

\author{
Mary Nolan \\ New York University
}

"Women in Dark Times" was the theme of a conference organized by Claudia Koonz held at the Rockefeller Conference Center in Bellagio, Italy, in August 1987. Twentyfive scholars from the United States, England, Germany, Italy, Spain, and Japan gathered to discuss private life and public policy in a variety of conservative and fascist regimes during the $1920 \mathrm{~s}, 1930 \mathrm{~s}$, and 1940s. The papers clustered around three broad themes: the new images and ideologies about women developed in this period; the character and consequences of policies toward women as workers, wives, and mothers; and resistance and adaptation. In the opening session, the papers discussed the controversies about interpreting fascism currently going on in Germany and Japan. Questions were raised about the essential characteristics of these "dark times": when they began and ended, and which elements were most formative for women. Participants discussed the respects in which women were traditional and those in which they were modern-in images, ideologies, and reality, as well as how this shaped their position in the various economies and nation states.

Although the conference did not focus exclusively on working-class women, several papers did. In addition, the conference offered the opportunity to compare how class influenced gender, whether in the pervasive images of "new women" that were deployed by a variety of political movements and states, in the policies toward economic mobilization and pronatalism, or in the forms of resistance and adaptation to oppressive regimes. Probably the most innovative and valuable aspect of the conference was its inclusion of scholars working not only on several European countries but also on Japan and China. The discussions of Asia presented surprising similarities 